\author{
В.Н. Калиновская, С. А. Эзериня \\ Институт лингвистических исследований РАН \\ (Россия, Санкт-Петербург) \\ kalinovskaiavn@yandex.ru \\ sezerspb@yandex.ru
}

\title{
СЕМАНТИЧЕСКИЕ ДЕРИВАЦИИ В РУССКОМ ЯЗЫКЕ ХІХ ВЕКА: СИСТЕМНОЕ И ИНДИВИДУАЛЬНО-АВТОРСКОЕ
}

\author{
«Свой среди чужих, чужой среди своих...» \\ (прецедентный текст)
}

В статье на материале лексики рассматриваются случаи семантической деривации как одной из тенденций, определяющих развитие лексической системы русского языка XIX века. В связи с данным процессом ставятся такие вопросы, как соотношение системного и индивидуально-авторского факторов, влияющих на изменения семантики отдельных слов и создание условий для формирования конкретных словообразовательных моделей на семантической мотивационной основе. Анализ лексических неологизмов, входящих в группу оттопонимических наименований этнонимов (кавказеи, ташкентеи, манчжуреи), показал чрезвычайную деривационную активность данной семантической мотивационной модели на концептуальном поле «свой - чужой»; установлено взаимодействие различных механизмов семантической производности (метонимии и метафоры) в этом процессе. Изучение подобных фактов языкового развития на широком текстовом фоне (различные по жанру и стилю, хронологии произведения разных авторов) и в исторической перспективе (варяzu) позволяет воспроизвести важный фрагмент языковой «картины мира», в котором исключительным образом проявился семантический потенциал анализируемой лексики. Анализ значительного количества употреблений каждой из рассматриваемых в статье лексических единиц обнаруживает общую тенденцию к переходу указанных наименований в разряд слов-ярлыков, слов-концептов.

Ключевые слова: русский язык XIX века, историческая лексикология, семантическая деривация, авторская неология, картина мира.

Фиксация семантической неологии при изучении различных типов и способов применения слова в текстах XIX века является одной из самых существенных и главных задач «Словаря русского языка XIX века». Традиционно значительное 
место при описании подобных языковых фактов отводится случаям экспрессивного и образного индивидуального употребления слова русскими писателями. О том, что «изучение семантики слова в ее соотношении с границами различной употребительности в речи» является важным положением историко-лексикологических исследований и что «в исследовании исторической судьбы отдельных слов особенно большую роль получает установление факторов, обусловливающих его изменчивость», написано достаточно давно [Сорокин 1965: 8]. Как отмечал В. В. Виноградов, «новое оригинальное употребление слова, если оно соответствует общим тенденциям смыслового развития языка, нередко определяет всю дальнейшую семантическую историю этого слова» [Виноградов 1950: 377]. Семантическая история рассматриваемой ниже целой группы слов свидетельствует: прецедентное употребление, закрепляясь в системе языка, формирует модель для последующих семантических изменений у аналогичных лексем. Выявление источников и механизмов реализации семантических потенций лексики русского языка в конкретный период его истории становится не менее важной проблемой при изучении подобных фактов языкового развития.

Среди лексических новаций в составе русского литературного языка XIX века можно выделить оттопонимическую неологию, а в ее ряду наименования лиц/ групп лиц по их территориальной принадлежности. Возникновение и семантическое развитие таких слов, как ташкентец/ташкентцыь, кавказец/кавказцы, туркестанец/туркестанцы, ман(b)чжурец/ман(ь)чжуриы, было обусловлено общественно-политическими и социокультурными факторами и связывалось с поздним (XVIII-XIX вв.) присоединением к Российской империи соответствующих территорий и последующим их освоением. ${ }^{1}$ В семантической структуре каждого слова выделяются однотипные для вышеприведенных лексических единиц значения: общие для всех слов 'коренные представители такой-то земли, области, территории и т. п.’ и факультативные, возникшие для обозначения лиц, не являющихся этническими представителями данной конкретной территории, но связанных с ней и длительно проживающих на ней по долгу службы, например 'люди, долго живущие на Кавказе' и 'русские военные (участники кавказских войн), расквартированные на Кавказе' или 'чиновники и военные из русской колонизационной администрации и подчиненных ей русских воинских частей, располагаемых в Ташкенте и на прилегающей к нему территории'. В семантике употреблений, производных от основного (формально мотивированного) значения слова, зеркально отражаются происходящие в реальной действительности изменения, касающиеся структуры населения конкретных территорий. Возникшие метонимическим способом расширительные, системно предсказуемые значения слов содержат важную историко-культурную информацию - о характере освоения («обживания») новых земель русскими, с чем, безусловно, связано формирование оценочного компонента

${ }^{1}$ О роли экстралингвистического фактора в этом процессе и проблеме вариативности подобных образований в связи с процессами нормализации русского литературного языка XVIII века см. подробнее: [Богородский 2004: 48-53]. 
в структуре значения. ${ }^{2}$ Ср. Капитан Тросенко был старый кавказец в полном значении этого слова, то есть человек, для которого рота, которою он командовал, сделалась семейством, крепость, где был штаб, - родиной, .. - человек, для которого все, что не было Кавказ, было достойно презрения. Л.Н. Толстой. Рубка леса (1855); Последствия <злоупотреблений русских чиновников> изложены ... на основании сообщений самих же русских ташкентцев: «не видя ни в чем перемены к лучшему, среднеазиатское население естественно начинает предпочитать русскому владычеству господство своих ханов, как бы забывая все беды, которые терпело от них». Исторические очерки России со времени Крымской войны до заключения Берлинского договора. 1855-1878 (1878). ${ }^{3}$

Приведенные примеры употребления указанных наименований по отношению к лицам иной этнической принадлежности могут представлять интерес также в аспекте культурной оппозиции «свой — чужой». «В философской антропологии различение “своего" и “чужого” — это проблема положения человека в окружающем мире. Человек не просто приспосабливается к среде, как это свойственно всему живому, но ... способен “войти” в другие культурные миры, в “чужую” духовную жизнь, следовательно, принципиально способен познать чужие миры и культуры» [Гапанович, Смольникова 2012: 12]. В современной философии эту оппозицию предлагается рассматривать в ее развитии - с позиции различий в исторических типах мировоззрения [Фельде 2015: 8]. Считается, что оппозиция «свой - чужой» культурно-антропологически обнаруживает себя через понятие «толерантности» [Там же: 7]. В приведенных выше цитатах, с точки зрения проявления «толерантности», рассматриваемые семантические дериваты получают оценочную коннотацию (со знаком +/-), что, на наш взгляд, повлияло на формирование мотивационной базы для соответствующих семантических неологизмов. Как видно из первой цитаты, положительная коннотация формируется за счет нейтрализации нового референтного признака у существительного кавказец благодаря контекстному окружению (старый, в полном значении этого слова), во второй - наоборот, наблюдается актуализация новой референтной семы (русские), а отрицательный оттенок создается содержанием всего контекста.

Подтверждением тому, что язык не есть только средство выражения мысли, но и форма ее становления (по В. Гумбольдту), можно считать возникновение особых употреблений у некоторых слов из этого ряда, выразивших чрезвычайно актуальные для изучаемой эпохи понятия. Вербализация понятий происходит на базе уже существующих в языковой системе словоформ, ранее прошедших ступень метонимизации. В этой связи особенно показательно развитие и закрепление за словом

${ }^{2}$ В этой связи представляется заслуживающей внимания точка зрения В. А. Богородского относительно роли контекста в формировании отрицательной коннотации у некоторых этнонимов с суффиксом -ец в их прямом значении, отличная от мнения других исследователей, объясняющих наличие таковой семантикой словообразовательного аффикса в сочетании с экстралингвистическим фактором (уничижительное отношение к инородцам) [Богородский 2004: 50].

${ }^{3}$ В качестве иллюстративного материала были использованы данные из картотеки «Словаря русского языка XIX века» (ИЛИ РАН). 
ташкентщы значения 'тип беспринципных дельцов (в первую очередь чиновников) ...', «этимология» которого восходит к известному очерку М.Е. СалтыковаЩедрина (употребление зафиксировано в качестве отдельной вокабулы в словаре XIX века [Михельсон 1896: 443-444]: «Ташкентцы» - имя собирательное. Те, которые думают, что это только люди, желающие воспользоваться прогонными деньгами в Ташкент, ошибаются самым грубым образом. "Ташкентец» - это просветитель. .. притом просветитель, свободный от наук, но не смущающчийся этим <...> Рестораны переполнены; шампанское льется рекой; облитые потом татары бегают, не сльша под собою ног; ассигнации мелькают в воздухе, как мухи в жаркий летний день... Кто сии ликующие, стремящиеся затмить своим ликованием ликование железнодорожных деятелей? Это они, это вчерашние рыбари, это сегодняшние ловкачи-ташкентцы, отведываюшие отечественного nuрога! М. Е. Салтыков-Щедрин. Господа ташкентцы (1869). Неслучайность выбора условного «термина» для наименования явления, связанного с распространением особого типа «цивилизаторов» XIX века, смысл которого писатель раскрывает на протяжении всего текста очерков, очевидна: Понять известное явление значит уже обобщить его, значит осуществить его для себя не в одной какой-нибудь частности, а в целом ряде таковых, хотя бы они, на поверхностный взгляд, имели между собой мало общего ... Вот почему я прошу читателя убедиться, что название «ташкентцы» отнюдь не следует принимать в буквальном смысле. О! если б все ташкентцы нашли себе убежище в Ташкенте! Мы могли бы сказать тогда: «Ташкент есть страна, населенная вышедшими из России, за ненадобностью, ташкентцами». Но теперь - разве мы можем по совести утверждать это? разве мы можем указать наверное, где начинаются границы нашего Ташкента и где они кончаются? не живут ли господа ташкентцы посреди нас? не рыскают ли стадами по весям и градам нашим? (Там же).

Данное употребление прочно закрепилось в языковом сознании русского человека не только применительно к российской действительности, но и в качестве слова-ярлыка, слова-концепта, означающего общецивилизационный феномен: Bom ведь как уважают нас, не без самодовольства думал он <английский офицер>; чтобы нас почтить, не жалеют даже и человеческих жертв ... И эти-то «ияиилизаторы», эти африканские ташкентцы имеют смелость толковать о просветительном значении своей миссии, о грубости и кровожадности дикарей! Дело. Научная хроника (1876, июль); И в истории Египта были свои «ташкентцы». Был в Египте сатирик, который вывел их на свет божий, пригвоздив к плитам говорящих камней. Д. Л. Мордовцев. Говор камней. Четырнадцать рассказов из жизни Древнего Египта (1895).

Таким образом, рожденный авторским словоупотреблением образ создает факт прецедентности и провоцирует семантический деривационный процесс на уровне системы: Инженер-строитель, подрядчик, купец, служащие на дороге, охранная стража, девица, ищущая приключений, иулера, содержатели притонов и т.п. - все это может быть окрещено словом «манчжсурец», если только у него имеются существенные признаки «манчжурца». У «манчжурца» на первом 
плане - поскорей и полакомей урвать кусок, не разбираясь в средствах. Вестник Европы (1904, ноябрь); Манчжурская авантюра в своей тлетворной атмосфере воспитала новый тип «манчжурца», который по своей циничности, по своим хищным инстинктам и по своему воровскому размаху превзошел даже пресловутого «таикентца». Русское богатство. Новые книги (1905, № 6).

Рассматриваемая семантическая мотивационная модель не является чем-то принципиально новым на данном концептуальном поле («свой - чужой»). В связи с этим любопытным представляется употребление авторами XIX века слова варяги. Не касаясь остающегося спорным вопроса его этимологии, отметим, что данная лексема в русском языковом сознании изначально ассоциировалась с 'представителями нормандских племен, норманнами', то есть так или иначе с «чужаками», роль которых в русской истории прослеживается начиная с древнейших летописей. Историческая реальность данного артефакта обнаруживает себя в тех значениях слова, которые появлялись у него в разные периоды существования русского языка, в том числе приобретающих символический характер: Я в последние четыре года много читал древних актов и пришел к следующему выводу: сказание о призвании варягов есть не факт, а миф, который гораздо важнее всяких фактов. Это так сказать преобразование русской истории ... Варяги - это губернаторы, председатели палат, секретари, становые, полицеймейстеры, одним словом все администраторы, которыми держится какой ни на-есть порядок в великой и обильной земле нашей. Это вся наша 14-ти-классная бюрократия, это 14-ти-главый змий поедучий, чудо поганое наших народных сказок. И. В. Павлов - М.Е. СалтыковуЩедрину 13 августа 1857 г. /Русская старина XСII (1892).

Тексты XIX века позволяют говорить о сложившейся многозначности слова, каждое из значений которого можно рассматривать как результат реализации изначально заложенных в его ядре семантических потенций слова ('чужой, пришлый, со стороны', ‘морской разбойник, пират', ‘мелочный торговец', индивидуальноавторское ‘поборник старины' - у А.С. Пушкина). В рамках темы выделим, прежде всего, значение 'чужой, пришлый, со стороны'. Обобщающий и одновременно оценочный характер значения давал возможность употребить «термин» варяги по отношению к разнопорядковым явлениям XIX века ${ }^{4}$ : Bbl не можете вообразить, что за война у нас теперь с Варягами и до каких печальных явлений доводит она. Пока, по-видимому, поле за прищельцами и отщепенцами; от того невнимание, равнодушие, а у некоторых даже и презрение ко всему, что не носит пятна западного. О. М. Бодянский - В. В. Ганке 30 апреля 1847 г. (1905); ...мыссль об устройстве паровых элеваторов давно уже врашается в одесском торговом мире, но ей

${ }^{4}$ На эту специфическую особенность, свойственную отдельным этнонимам, лингвисты уже указывали, например, в связи с употреблением наименования немщы по отношению ко всем выходцам из Европы [Богородский 2004: 48]. По-видимому, неслучайно в Послании Ивана Грозного (1573 г.) оба слова употреблены в одном контексте и составляют единый образ, запечатленный в языковом сознании русского человека: «...и мы потому так писали, что в прежних хрониках и летописцех писано, что с великим государем самодержцем Георгием-Ярославом на многих битвах бывали варяги, а варяги — немцы» [Цит. по: Словарь 2006: 29-30]. 
суждено вероятно еще долго только вращаться, пока не явятся какие-нибудь варяги из Франции или Англии и не сделаются князьями скорой и удобной погрузки судов. Дело (1883, № 12); Когда были опрошены все более или менее известные врачи, тверская управа обратилась к другому разряду медиков, и нашла, кажется, в Орле некий медицинский раритет, - согласившийся ехать в Тверь. .. Варяги приехали в чуждое им учреждение и начали хозяйничать. Не прошло и 4 месяцев со дня ухода д-ра Литвинова, как в Бурашевской колонии стали применяться немыслимые до сих пор обычаи Чеховской «палаты номер шесть». Русская мысль (1896, № 1).

Цепь закономерностей, выявленных при изучении семантических процессов на примере рассмотренных языковых фактов, и их последствий для последующей словообразовательной деятельности (ташкентствовать, маньчжурка), фразеологизации новых сочетаний (маньчжурская эпопея, маньчжурские деньги) заставляет согласиться с утверждением Ю.С. Сорокина относительно того, что «прямая номинативная связь оказывается сильнее и устойчивее словообразовательных связей в силу своей исключительности и универсальности, в силу того, что слово становится общим постоянным обозначением известного предмета наших мыслей со всеми возможными его признаками. Это приводит к изоляции слова, к отделению его от первоначального гнезда слов» [Сорокин 1965: 14].

\section{Литература}

Богородский В.А. О словообразовании этнонимов в русском языке XVIII века // Русская и сопоставительная филология: лингвокультурологический аспект /отв. ред. Н. А. Андрамонова. Казань: Казан. гос. ун-т. 2004. С.48-53.

Виноградов В. В. Из истории современной русской лексики // Известия Академии наук СССР, Отделение литературы и языка. М., 1950. Т. IX. Вып. 5. С. 376392.

Гапанович E. А., Смольникова Н. С. Оппозиция «свой - чужой» (теоретический аспект) // Филология, искусствоведение и культурология: тенденции развития: материалы международной заочной научно-практической конференции. (12 марта 2012 г.) [Электронный ресуpc]. URL: https://sibac.info/conf/philolog/ix/27002

Михельсон М.И. Ходячие и меткие слова. СПб. 2-е издание, 1896.

Словарь 2006 - Словарь обиходного русского языка Московской Руси XVIXVII веков / Под ред. О. С. Мжельской. Вып. 2. СПб.: Наука, 2006. 340 с.

Сорокин Ю.С. Развитие словарного состава русского литературного языка в 30-90-е гг. XIX в. Ленинград: Наука. 1965. 565 с.

Фельде В.Г. Оппозиция «свой - чужой» в культуре: дис. ... канд. филос. наук / Омск. гос. пед. ун-т. Омск, 2015. 152 с. 


\author{
V.N. Kalinovskaya, S. A Ezerynya \\ Institute for Linguistic Studies, Russian Academy of Sciences \\ (Russia, Saint-Petersburg) \\ kalinovskaiavn@yandex.ru \\ sezerspb@yandex.ru
}

\title{
SEMANTIC DERIVATION IN THE 19 ${ }^{\mathrm{TH}}$ CENTURY RUSSIAN LANGUAGE: THE SYSTEM-BASED AND THE AUTHORS' INDIVIDUAL
}

The article focuses on some cases of lexical semantic derivation as an important source of further development of the $19^{\text {th }}$ century Russian lexical system. The given process has made actual the problem of correlating the system-based and the authors' individual factors which exert a considerable influence on semantic shifts in the meaning of certain words as well as on forming of new word-building patterns based on certain semantic motivational grounds. The analysis of lexical neologisms from the group of ethnonyms motivated by toponyms (kavkazets, tashkentets, manchzhurets) has displayed high derivational activity of the given semantic motivational pattern in the conceptual domain 'home' - 'alien', correlation of various semantic mechanisms (including metonymy and metaphor) involved in the process being found as well. Observation of such-like linguistic facts on the wide textual basis and in historical perspective (varyagi) provides new insights into a significant fragment of linguistic world image.

Key words: $19^{\text {th }}$ century Russian language, historical lexicology, semantic derivation, authors' neology, linguistic world image.

\section{References}

Bogorodskii V.A. [On the word formation of ethnonyms in the Russian language of the XVIII century]. Russkaya i sopostavitel'naya filologiya: lingvokul'turologicheskii aspekt [Russian and comparative philology: linguistic and culturological aspect]. Kazan: Kazan State Univ. Publ., 2004, pp. 48-53. (In Russ.)

Felde V. G. Oppozitsiya «svoi - chuzhoi»v kul'ture. Diss. kand. filol. nauk [Opposition «home - alien» in culture. Cand. phil. sci. diss.]. Omsk, 2015. 152 p.

Gapanovich E.A., Smol'nikova N.S. [Opposition «home - alien» (theoretical aspect)]. Filologia, isskustvovedenie I kul'turologiya: tendentsii razvitiya: materialy mezhdunarodnoi zaochnoi nauchno-practicheskoi konferentsii [Philology, art and cultural studies: development trends: materials of the international virtual scientific-practical conference] Novosibirsk: SIBAC Publ. 2012, pp. 11-17. Available at: https://sibac.info/ conf/philolog/ix/27002_(In Russ.)

Mikhelson M.I. Khodyachie $i$ metkie slova [Popular and striking words]. $2^{\text {nd }}$ ed. St. Petersburg, 1896. 
Slovar' 2006 - Slovar' obikhodnogo russkogo yazyka Moskovskoi Rusi XVI-XVII vekov [Dictionary of the colloquial Russian language of Moscow Rus of the XVI-XVII centuries]. Issue 2. St. Petersburg, Nauka Publ, 2006. 340 p.

Sorokin Yu. S. Razvitie slovarnogo sostava russkogo literaturnogo yazyka $v 30-90-e$ gg. $X I X v$. [The evolution of the vocabulary of the Russian literary language in the 30-90-s of the XIX century]. Leningrad, Nauka Publ., 1965. 565 p.

Vinogradov V.V. [From the history of modern Russian vocabulary]. Izvestiya Akademii nauk SSSR, Otdelenije literatury i jazyka. Moscow, Academy of Sciences of the USSR Publ., vol. IX, no. 5, pp. 376-392. (In Russ.) 